See Article page e207.

\section{Commentary: Protecting the powerhouse of the cell: The next frontier of myocardial protection?}

\author{
Edward Buratto, MBBS, PhD, FRACS, ${ }^{\mathrm{a}, \mathrm{b}, \mathrm{c}}$ and \\ Igor E. Konstantinov, MD, PhD, FRACS ${ }^{a, b, c, d}$
}

It appears that some 2 billion years ago, bacteria capable of aerobic metabolism were endocytosed by early eukaryotic cells and evolved into mitochondria. This symbiotic relationship conferred an enormous advantage by providing a means of aerobic metabolism for eukaryotic cells, paving the way for the evolution of complex multicell organisms. In normal conditions, the human myocardium is completely reliant on aerobic metabolism, which takes place in mitochondria. In ischemic conditions, such as those generated by aortic crossclamping in cardiac surgery or organ procurement, there is a switch to anaerobic metabolism. The process of ischemia-reperfusion causes mitochondrial injury that may be an important contributor to myocardial dysfunction. Recently, mitochondria have been recognized as a potential target for preventing ischemia-reperfusion related myocardial injury in several settings, including acute myocardial ischemia, organ transplantation, and right ventricular dysfunction. ${ }^{1-5}$

Song and colleauges ${ }^{6}$ report the effects of a mitochondrial-specific antioxidant, Mito-Tempo, on an in vitro mouse model of cardioplegic ischemia-reperfusion. Mito-Tempo, which contains 2 compounds-triphenylphosphonium and piperidine nitroxide-is a lipophilic

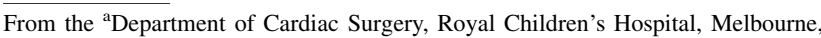
Victoria, Australia; 'bepartment of Paediatrics, University of Melbourne, Melbourne, Victoria, Australia; 'Heart Research Group, Murdoch Children's Research Institute, Melbourne, Victoria, Australia; and ${ }^{\mathrm{d}}$ Melbourne Centre for Cardiovascular Genomics and Regenerative Medicine, Melbourne, Victoria, Australia.

Disclosures: The authors reported no conflicts of interest.

The Journal policy requires editors and reviewers to disclose conflicts of interest and to decline handling or reviewing manuscripts for which they may have a conflict of interest. The editors and reviewers of this article have no conflicts of interest.

Received for publication July 5, 2021; revisions received July 5, 2021; accepted for publication July 7, 2021; available ahead of print July 14, 2021.

Address for reprints: Igor E. Konstantinov, MD, PhD, FRACS, Department of Cardiac Surgery, Royal Children's Hospital, Flemington Rd, Parkville, VIC 3052, Australia (E-mail: igor.konstantinov@rch.org.au).

J Thorac Cardiovasc Surg 2022;164:e227-8 0022-5223/\$36.00

Crown Copyright $\subset 2021$ Published by Elsevier Inc. on behalf of The American Association for Thoracic Surgery

https://doi.org/10.1016/j.jtcvs.2021.07.009
}

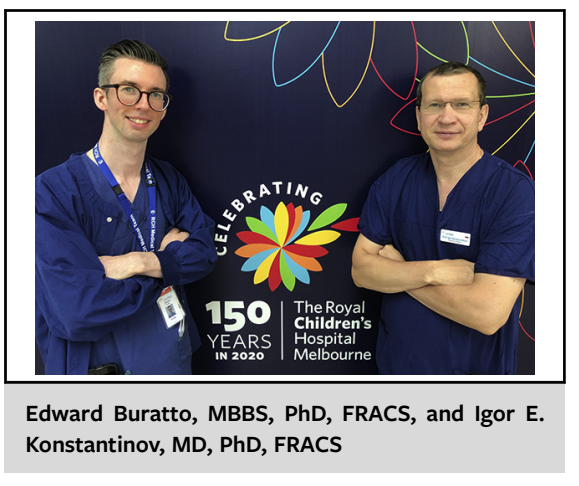

CENTRAL MESSAGE

Mitochondria represent important new targets for protection during ischemia-reperfusion associated with cardiac surgery.

molecule. Being lipophilic, it can easily pass through the phospholipid membranes and accumulate within mitochondria where it acts as a superoxide scavenger, thus preventing oxidative injury. Song and colleauges ${ }^{6}$ demonstrate that treatment with Mito-Tempo had a range of beneficial effects on vessels including improved endothelium dependent vasodilatation, depressed intracellular calcium influx, and significantly reduced levels of reactive oxygen species within endothelial cells. Importantly, these beneficial effects were observed in both non-diabetic and diabetic experimental models, resulting in decreased microvascular dysfunction following ischemia-reperfusion.

Our current techniques of myocardial protection continue to rely on electrolyte induced cardiac arrest in diastole and hypothermia to minimise myocardial oxygen demand, with or without substrate enhancement, in order to reduce ischemia-reperfusion induced damage to the myocardium. These are essentially the same techniques described by the pioneering work of Buckberg and colleagues in the 1970s, ${ }^{7}$ with very few major advances in the intervening period. However, it appears that mitochondria may represent an important new target. It has previously been shown that mitochondrial transplantation into cardiomyocytes is a potentially effective strategy to improve myocardial recovery in the setting of ischemiareperfusion, both in cardiac surgery and cardiac procurement for transplantation. Song and colleauges ${ }^{6}$ have added to this evidence by showing that protecting mitochondria from reactive oxygen species may preserve microvascular function in the setting of ischemia-reperfusion. Given the 
lipophillic properties of Mito-Tempo, it is possible it may also be able to diffuse into the myocardium and protect mitochondria within the cardiomyocytes from ischemiareperfusion injury and, thus, directly protect the myocardium. The latter, however, is yet to be determined. The obvious benefit of Mito-Tempo compared to the more complex techniques involved in mitochondrial transplantation is the ease in which it could be incorporated into our current cardioplegia solutions.

Will therapies targeted at mitochondria provide a paradigm change in myocardial protection? This remains to be seen, yet the early pre-clinical data appear promising!

\section{References}

1. Guariento A, Piekarski BL, Doulamis IP, Blitzer D, Ferraro AM, Harrild DM, et al. Autologous mitochondrial transplantation for cardiogenic shock in pediatric patients following ischemia-reperfusion injury. J Thorac Cardiovasc Surg. 2020 [In press].

2. Emani SM, Piekarski BL, Harrild D, Del Nido PJ, McCully JD. Autologous mitochondrial transplantation for dysfunction after ischemia-reperfusion injury. J Thorac Cardiovasc Surg. 2017;154:286-9.

3. Hsu CH, Roan JN, Fang SY, Chiu MH, Cheng TT, Huang CC, et al. Transplantation of viable mitochondria improves right ventricular performance and pulmonary artery remodeling in rats with pulmonary arterial hypertension. $J$ Thorac Cardiovasc Surg. 2020 [In press].

4. Weixler V, Lapusca R, Grangl G, Guariento A, Saeed MY, Cowan DB, et al. Autogenous mitochondria transplantation for treatment of right heart failure. J Thorac Cardiovasc Surg. 2021;162:e111-21.

5. Buratto E, Konstantinov IE. Commentary: mitochondrial transplantation for ischemia-reperfusion injury-a new revolution or tilting at windmills? J Thorac Cardiovasc Surg. 2020 [In press].

6. Song Y, Xing H, He Y, Zhang Z, Shi G, Wu S, et al. Inhibition of mitochondrial reactive oxygen species improves coronary endothelial function after cardioplegic hypoxia/reoxygenation. J Thorac Cardiovasc Surg. 2022;164:e207-26.

7. Buckberg GD. A proposed "solution" to the cardioplegic controversy. J Thorac Cardiovasc Surg. 1979;77:803-15.
Commentary: Targeting mitochondrial injury after plegic arrest: SK-ipping the endothelial tempo or not?

\author{
Ilias P. Doulamis, $\mathrm{MD}, \mathrm{PhD},{ }^{\mathrm{a}}$ and \\ Aspasia Tzani, MD, $\mathrm{PhD}^{\mathrm{b}}$
}

In this issue, Song and colleagues ${ }^{1}$ demonstrated that Mito-Tempo improved endothelium-dependent relaxation response and suppressed intracellular $\mathrm{Ca}^{2+}$ accumulation following cardioplegic hypoxia and reoxygenation. The authors suggest that these results are mediated by enhanced endothelial SK channel activity through inhibition of mitochondrial reactive oxygen species (ROS). The authors also concluded that coronary arteries of either normoglycemic

From the ${ }^{\mathrm{a}}$ Department of Cardiac Surgery, Boston Children's Hospital; and ${ }^{\mathrm{b}}$ Brigham and Women's Hospital Heart and Vascular Center, Harvard Medical School, Boston, Mass.

Disclosures: The authors reported no conflicts of interest.

The Journal policy requires editors and reviewers to disclose conflicts of interest and to decline handling or reviewing manuscripts for which they may have a conflict of interest. The editors and reviewers of this article have no conflicts of interest.

Received for publication June 22, 2021; revisions received June 22, 2021; accepted for publication June 23, 2021; available ahead of print June 29, 2021.

Address for reprints: Ilias P. Doulamis, MD, PhD, Department of Cardiac Surgery, Boston Children's Hospital, Harvard Medical School, Boston, MA 02115 (E-mail: doulamis.i@gmail.com).

J Thorac Cardiovasc Surg 2022;164:e228-9

0022-5223/\$36.00

Copyright (c) 2021 by The American Association for Thoracic Surgery

https://doi.org/10.1016/j.jtcvs.2021.06.050

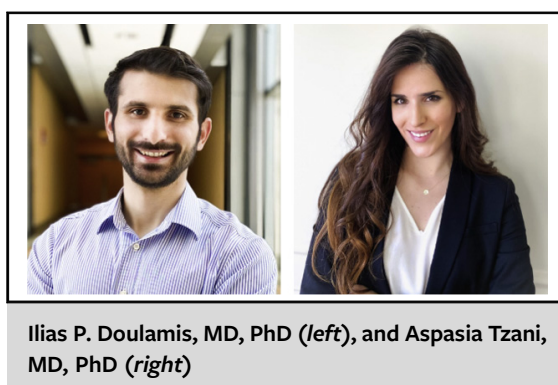

CENTRAL MESSAGE

Mito-Tempo improves

endothelium-dependent relaxa-

tion response and suppresses

intracellular $\mathrm{Ca}^{2+}$ accumulation

after cardioplegic hypoxia/reoxy-

genation in vitro, yet in vivo

studies are necessary.

or diabetic murine with Mito-Tempo showed enhanced endothelium-dependent relaxation in response to either a SK activator or an endothelium/nitric oxide-dependent vasodilator in a dose-dependent response.

Mitochondrial dysfunction plays a major role in myocardial injury following ischemia-reperfusion and is merely associated with ROS accumulation, which are byproducts of the altered metabolism of the cardiomyocytes. $^{2}$ Mito-Tempo is reported to be a mitochondriatargeted antioxidant providing protection either against 